\title{
Causes of long-term deflections of large-span pre-stressed concrete box girders and recommendations on how to avoid these
}

\author{
V. Křístek ${ }^{*}$, L. Vráblík, V. Hrdoušek \\ Czech Technical University in Prague, Czech Republic \\ *Corresponding author: vladimirkristek@seznam.cz
}

\begin{abstract}
The results of the presented solutions and the developed analytical and design methods will help in creating the sufficient theoretical tools for the reliable and economic structural design of bridges without deflection impairments. The paper reviews the causes of under-estimation of long-term future deflections. Special attention is placed on prestressing - a procedure to find the optimal arrangement of tendon layout - is presented, facilitating the avoidance of tendons contributing to deflection increases. A developed computer program is freely available and a method of repair procedure and a repair example, as well as recommendations for the design practice are also presented.
\end{abstract}

KEY WORDS: bridge, creep, deflection, pre-stressed concrete, shear

\section{GENERAL GUIDELINES}

The design of structures is more and more directed towards the entire lifetime design with multiple concurrent objectives. Apart from durability, the most important factor in the whole life design of reinforced and, in particular, pre-stressed concrete bridges, is the Service Limit State. From this point of view, pre-stressed concrete bridges are very sensitive to a long-term increase of deflections. This phenomenon has a paramount importance for serviceability, durability and the long-time reliability of such bridges.

Due to excessive deflections, several bridges had to be either closed or repaired well before the end of their initially projected lifespan. The cost of reduced service life of structures is tremendous for society, the owners and users. In fact, it greatly exceeds, in strictly economic terms, the cost of catastrophic failure, due to a badly predicted safety margin.

Reliable prediction of bridge deflections during their construction, as well as during their service life, is of crucial importance for achieving good durability and long-term serviceability. Obviously, the difficulty of predicting deflections is closely related to the properties of concrete (strength, elastic modulus, nonlinearity, creep, shrinkage, etc.), both initially and over time.

The long-term deflection behaviour of long-span pre-stressed concrete box girder bridges has often deceived engineers monitoring the deflections. A survey of many bridges monitored in various countries showed that all of them have experienced similar deflection histories. It has frequently been experienced that the box girders of many pre-stressed concrete bridges deflected far more than predicted in design. The deflection evolution has often been counterintuitive, with slowly growing deflections in the early years, followed later by a rapid and excessive deflection growth. 
Six different causes of the deflection problems may be discerned:

1 Design based on an obsolete, oversimplified and unrealistic model for predicting creep, and the shrinkage properties of concrete, or of cross sections of concrete girders (Bažant 2000, Kř́stek et al. 2006).

2 An obsolete and unrealistic method of time-dependent analysis of structural effects of creep and shrinkage, based, for instance, on assuming the creep and shrinkage properties to be homogeneous throughout the cross section and ignoring the effects of differences of shrinkage and drying creep between the top and bottom slabs of the box girder (Krístek et al. 2006), which result from differences in drying half-times engendered by differences principally in slab thickness and secondarily in temperature history.

3 Lack of updating of the long-time creep and shrinkage predictions by means of short-time (1 month) creep and shrinkage tests and water loss tests of the particular concrete to be used (Bažant and Baweja 2000).

4 Absence of statistical deflection predictions, ignoring the large random scatter in concrete creep and shrinkage effects, and especially the fact that the total observed deflection is the difference of two large numbers - the deflection due to external loads, and the deflection due to pre-stress (a difference of large numbers is greatly sensitive to a small change in one of these numbers and may thus result in a significant change of thedifference, i.e., in a significant change of the total deflection value).

5 Incorrect and harmful tendon layout - some tendon layouts benefiting the stress state can atthe same time be harmful from the deflection viewpoint. Therefore, bridge design should be performed on two different levels: not only the common stress analysis, but also optimization of pre-stressing tendon layout to minimize deflections.

6 An oversimplified structural model-particularly the use of the classical mechanics of beam bending, based on the Bernoulli-Navier hypothesis of cross-sections remaining plane, while the true behavior is three-dimensional, with a strong shear lag, due to large shear deformations in the webs and plates.

Let us now discuss point 5 in more detail.

\section{DEFLECTION INCREASE DUE TO INCORRECT AND HARMFUL TENDON LAYOUT}

The choice of pre-stress tendon layout, i.e., the location and profile, is often governed by construction stages, as well as the cross-section geometry. But it is important to optimize the layout of tendons, so as to minimize deflections. Low deflections during the cantilever construction stages do not ensure acceptable deflections during the service life. The tendons installed during cantilever erection stages are usually very efficient during construction. However, after changes of the structural system (e.g. closing of the mid-span joints) to make the structure continuous, the cantilever tendons might not significantly inhibit the long-term deflection growth because creep produces additional forces, due to the redundancy of the new structural system.

The consequences of the tendon layout for deflections have been elucidated and a method to assess them quantitatively has been developed (Krrístek and Vráblík, 2007). The advantage of this method is its ease of application, which allows the optimal tendon layout to be readily determined. The method has been programmed and is freely available on a web site and is proposed as a simple design aid avoiding expensive solutions. The practicing engineers can benefit in the design of sensitive bridges from the computer program OPTI 1.1, which has been developed at the Czech Technical University in Prague to make the assessment of the tendon layout immediately accessible to any engineer. This program is free to download from the Internet address: http://concrete.fsv.cvut.cz/veda/science_en.php. It suffices to fill out the boxes for the data on the bridge and its tendon layouts, and the output 
is the deflection contributions of the individual tendons. The location of a tendon that is most efficient for reducing deflections can be determined in such a way.

Let us now present an example from practice, elucidating the significance of tendon layout and the efficiency of various layouts in reducing the deflections. The example is the bridge over the river Labe (Elbe) in Mělník: A three-span tapered continuous box girder (with spans $72.05+146.2+72.05$ m; Fig. 1), built in 1992 in Central Bohemia and erected using the cantilever technology. We are interested in identifying a possible unsuitable tendon layout that would be harmful, causing a long-time increase (rather than a decrease) of the mid-span deflection.

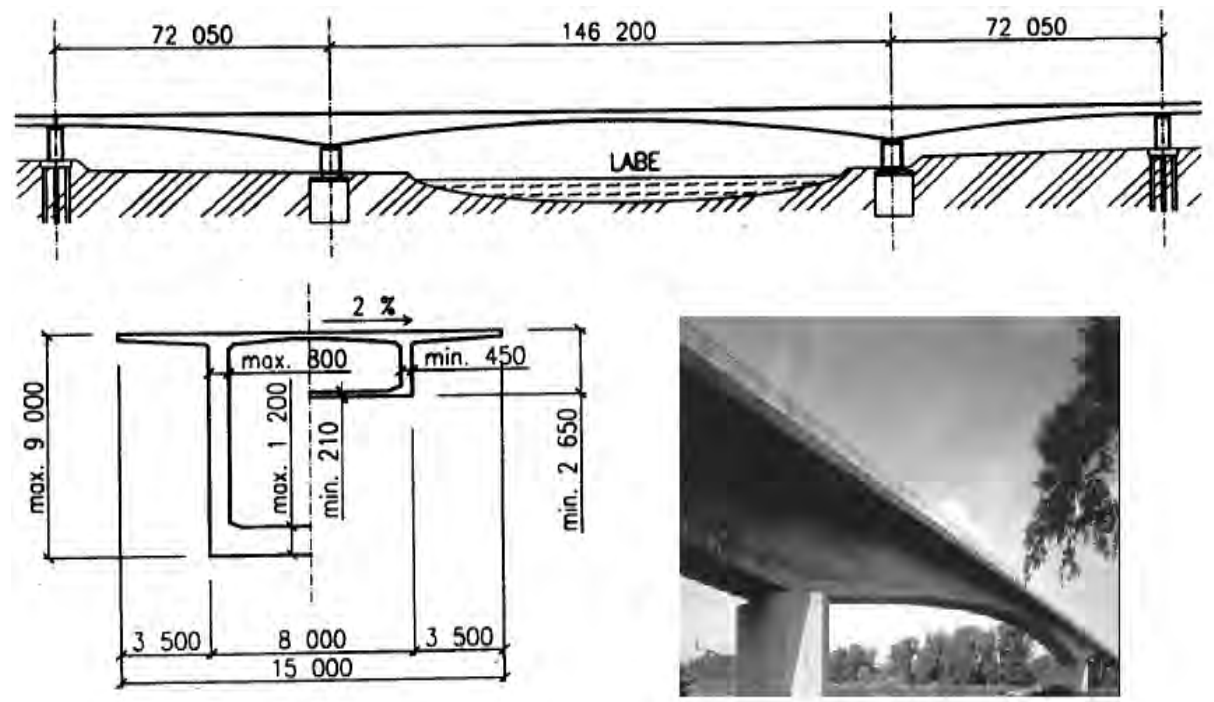

Figure 1: Bridge over the River Labe (Elbe) in Mělník.

Tendons of several categories were installed during the individual stages of the construction process (Fig. 2). The effects of individual tendons were evaluated by applying the above mentioned computer program OPTI 1.1 developed for this purpose. As a result, $22 \%$ of the all pre-stressed tendons have been identified that affect this bridge unfavorably, i.e., contribute to an increase of deflection. The tendons located at the bottom surface of the first and third spans (see Fig. 2), prove to be extremely harmful, since all of them enhance the deflections in the central region of the main span. Among the tendons located at the top surface, installed during cantilever erection, the straight ones, which are passively anchored in the vicinity of internal supports and follow the top surface, are harmful. In this particular bridge, the unfavorable tendons in the first, as well as the third, span are anchored typically at distance of approximately $15 \mathrm{~m}$ from the ends of the bridge, and the unfavorable tendons inthe main span are anchored typically at distances of approximately $30 \mathrm{~m}$ from the mid-span (see Fig. 2).

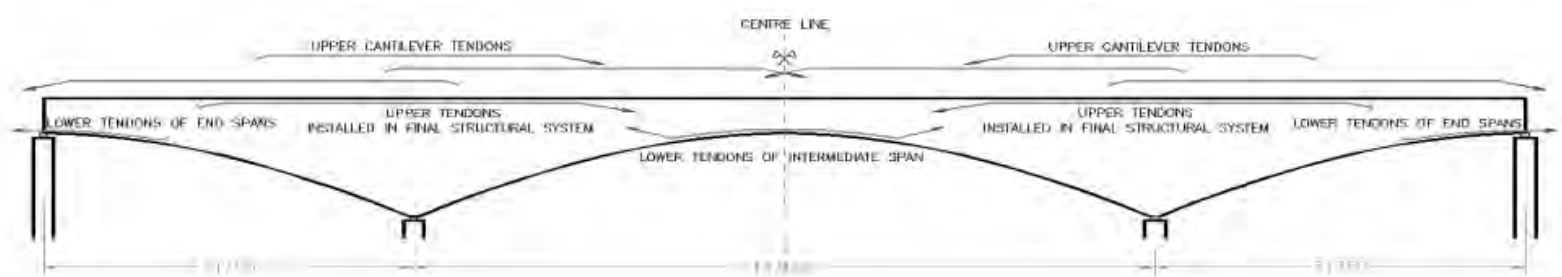

Figure 2: Schematic layout of pre-stressed tendons 


\section{EXAMPLE OF RECONSTRUCTION}

An example is the excessive deflection that required reconstruction of the box girder bridge over river Labe (or Elbe) in Děčín in North Bohemia (Fig. 3). The structural system of this bridge is a three-span continuous box girder (with spans $62.5+104+62.5$ m; Fig. 3). It is tapered in shape and was erected using the cantilever technology.

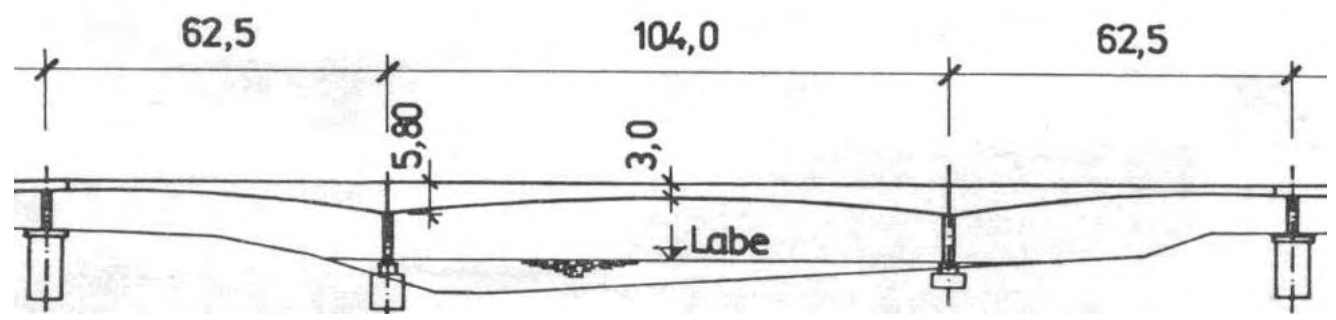

Figure 3: Bridge over river Labe (or Elbe) in Děěín, Czech Republic

The bridge was monitored since its erection in 1993. The mid-span deflection increased annually by about $8 \mathrm{~mm}$. The total difference between the theoretical and measured road levels reached about $140 \mathrm{~mm}$ just before the start of reconstruction. There are several probable reasons for the excessive deflection:

- a lower value of modulus of elasticity of concrete;

- neglect of the shear effect on deflection in the design;

- incorrect compliance function for the evolution of creep in time; and

- a higher influence of relaxation of pre-stressed steel.

In the reconstruction, the stiffness of the structure was increased by adding external prestressed tendons, as shown in Fig. 4, 5.

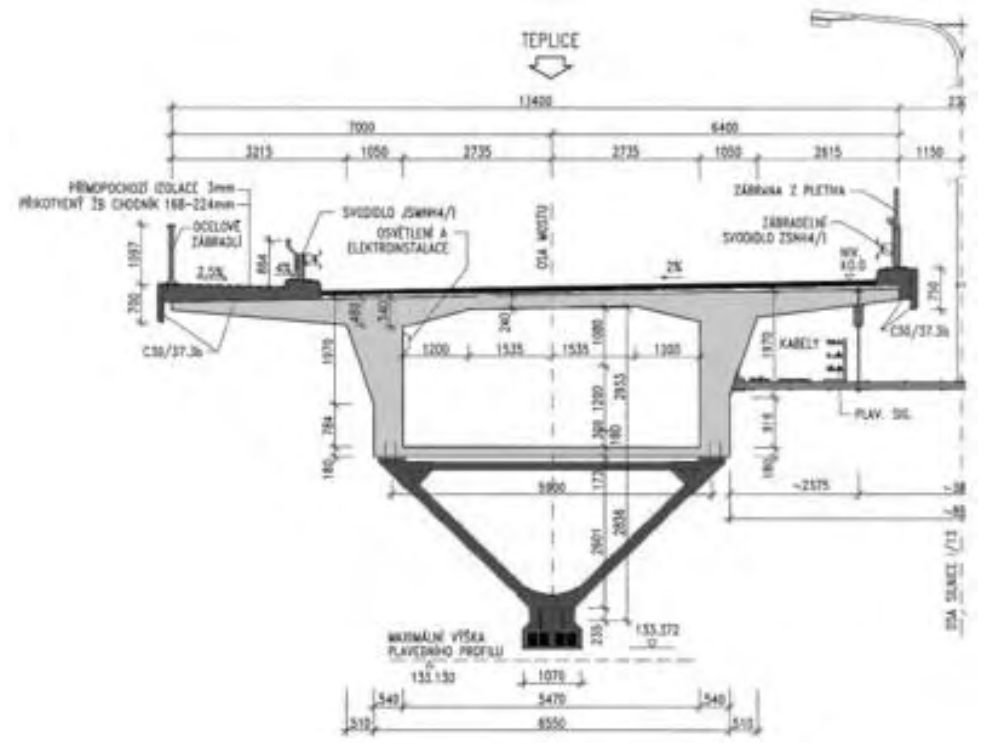

Figure 4: Cross section (Děčín) 


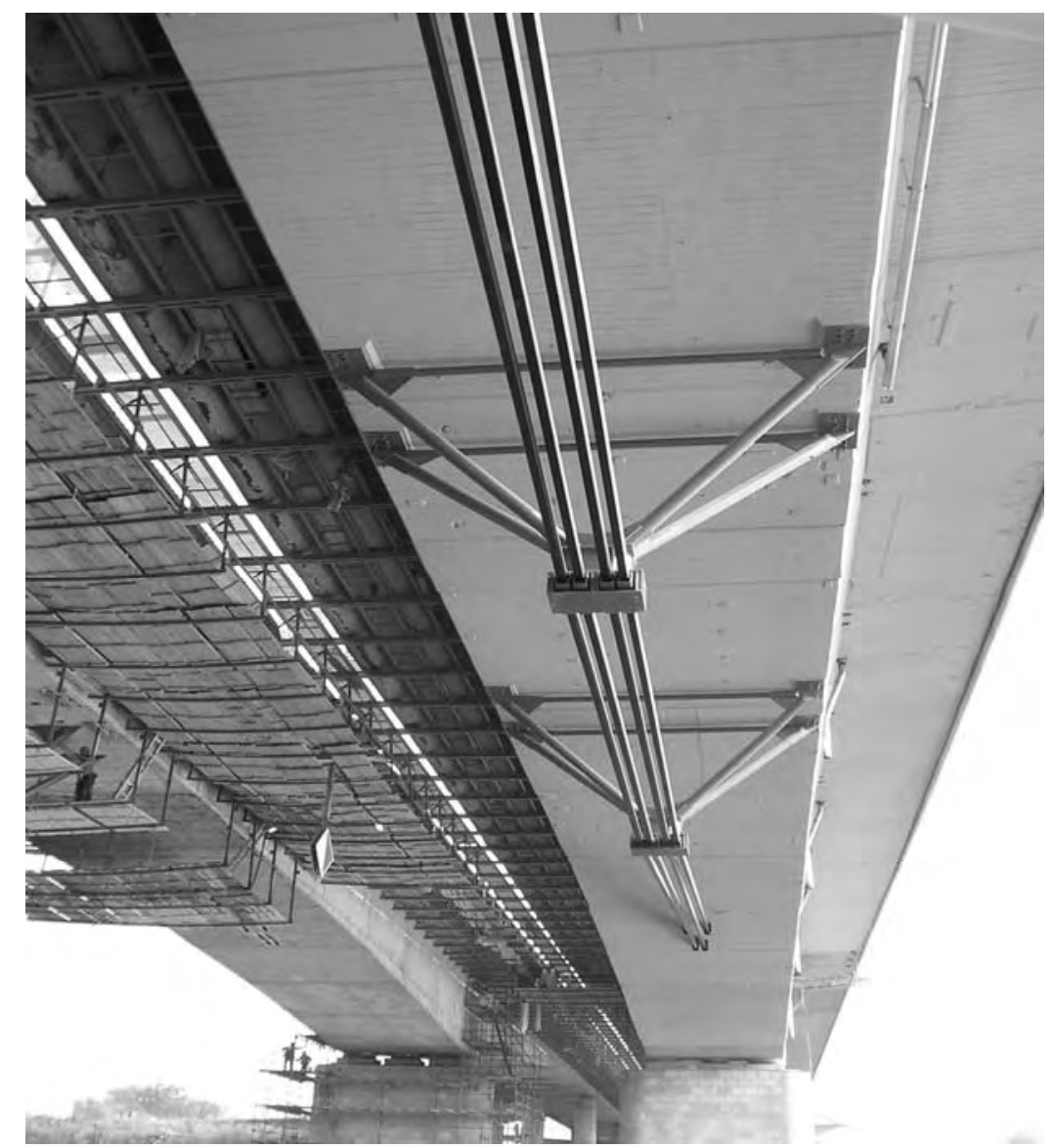

Figure 5: View of external tendons (Děčín)

\section{CONCLUSIONS}

The lesson to be learned from the deflections of the existing bridges is that bridge design should be performed in two different and equally important phases - not only the usual stress analysis, but also the optimization of pre-stressing tendon layout. The latter is a necessity for ensuring acceptable long-term deflections.

\section{ACKNOWLEDGMENT}

Support of the Ministry of Transportation of the Czech Republic, through Grant Project No. 1F45E/020/120, is gratefully acknowledged.

\section{REFERENCES}

Křístek, V., Vráblík, L, Bažant, Z.P., Li, G., Yu, Q., 2008. Mis-prediction of Long-Term Deflections of Prestressed Box Girders: Causes, Remedies and Tendon Layout Effect, Proc.of Concreep8.

Bažant, Z.P. 2000. Criteria for rational prediction of creep and shrinkage of concrete. Adam Neville Symposium: Creep and Shrinkage---Structural Design Effects, ACI SP--194, A. AlManaseer, ed., Am. Concrete Institute, Farmington Hills, Michigan, 237-260 (updated from Materials and Structures, RILEM, Paris, Vol. 28, pp. 357-365). 
Bažant, Z.P., and Baweja, S. 2000. Creep and shrinkage prediction model for analysis and design of concrete structures: Model B3. Adam Neville Symposium: Creep and Shrinkage--Structural Design Effects, ACI SP-194, A. Al-Manaseer, ed., Am. Concrete Institute, Farmington Hills, Michigan, 1-83.

Kř́stek, V., Bažant, Z.P., Zich, M., and Kohoutková, 2006. Box girder deflections: Why is the initial trend deceptive? ACI Concrete International 28 (1), 55-63.

Kř́istek, V., Vráblík, L., 2007: Optimization of tendon layout to avoid excessive deflections of long-span pre-stressed concrete bridges, Concrete Engineering International, Vol. 11, No.1. 